\title{
ANALISA PERENCANAAN KEBUTUHAN MATERIAL PADA PERUSAHAAN MANUFAKTUR KERTAS DENGAN METODE MATERIAL REQUIREMENT PLANNING (MRP)
}

\author{
Sri Lestari, Distian Dwi Nurdiansah \\ Program Studi Teknik Industri, Fakultas Teknik, Universitas Muhammadiyah Tangerang \\ Email: srilestari2606@gmail.com; distian12@gmail.com
}

\begin{abstract}
Abstrak - Perkembangan dunia usaha saat ini mengalami laju pertumbuhan yang sangat pesat. Perencanaan pengadaan material yang tepat akan mampu memperlancar kegiatan produksi perusahaan. Kegiatan proses produksi pada perusahaan sering mengalami masalah seperti ketidaktepatan waktu produksi, yang disebabkan oleh keterlambatan kedatangan bahan baku, dan kerusakan bahan baku karena terlalu lama menyimpan dalam gudang. Penelitian ini bertujuan untuk merencanakan kebutuhan di masa mendatang dengan pendekatan Material Requirement Planning (MRP) dengan cara melakukan forecasting, pembuatan Master Production Schedule (MPS), Material Requirement Planning (MRP) dan melakukan analisis biaya dari 5 metode yang digunakan. Hasil dari penelitian ini adalah peramalan permintaan produk akan digunakan metode regresi linear dan metode perencanaan kebutuhan material yang efektif dengan biaya paling murah adalah dengan menggunakan metode Lot For Lot (LFL) sebesar \$164.48. Penerapan metode Lot For Lot mampu menurunkan biaya sebesar 90,06\% dibandingkan dengan metode Fixed Period Requirements (FPR) yang dipakai perusahaan.
\end{abstract}

Kata kunci: Fixed Period Requirements; Forecasting; Lot For Lot; Material Requirement Planning

\begin{abstract}
The development of the business world is currently experiencing a very rapid growth rate. Planning for the proper procurement of materials will be able to facilitate the company's production activities. Production process activities in companies often experience problems such as inaccurate production, which is caused by delays in the arrival of raw materials, and damage to raw materials due to too long storing in warehouses. This study aims to plan future needs with the Material Requirement Planning (MRP) approach by doing forecasting, making the Master Production Schedule (MPS), Material Requirement Planning (MRP) and conducting a cost analysis of the five methods used. The results of this study are forecasting product demand will be used linear regression method, and effective material requirements planning method with the lowest cost is to use the Lot For Lot (LFL) method of \$164.48. The application of the Lot For Lot method can reduce costs by $90.06 \%$ compared to the Fixed Period Requirements (FPR) method used by the company.
\end{abstract}

Keywords: Fixed Period Requirements; Forecasting; Lot For Lot; Material Requirement Planning

\section{PENDAHULUAN}

Perkembangan dunia usaha sekarang ini mengalami laju pertumbuhan yang sangat pesat. Pertumbuhan yang pesat ini tentunya akan menimbulkan persaingan dunia usaha antara satu perusahaan dengan perusahaan lainnya. Dalam menghadapi persaingan bisnis ini, perusahaan harus efektif untuk menentukan strategi bisnisnya sehingga diharapkan perusahaan tersebut dapat survive dalam bidang usahanya.

Penentuan besarnya persediaan penting untuk perusahaan, karena persediaan dapat berdampak pada keuntungan perusahaan. Kurangnya strategi yang tepat akan dapat menentukan keuntungan perusahaan. Adanya persediaan yang terlalu besar dibandingkan dengan kebutuhan perusahaan tentunya akan menambah biaya perusahaan dalam biaya pemesanan (ordering cost), biaya penyimpanan (carrying cost), serta kemungkinan adanya kerusakan pada kualitas yang tidak dapat dipertahankan, sehingga dapat merugikan perusahaan. Demikian sebaliknya jika persedian barang terlalu kecil akan menyebabkan perusahaan tidak dapat produksi dan 
perusahaan akan mengalami kerugian juga.

Material Requirement Planning (MRP) merupakan salah satu metode yang digunakan untuk pengendalian bahan baku. MRP merupakan sistem informasi yang digunakan untuk merencanakan kebutuhan bahan baku yang dibutuhkan kegiatan membuat produk yang telah ditentukan (Greasley, 2008; Arif, Supriyadi, \& Cahyadi, 2017). Penerapan MRP mampu mengendalikan persediaan bahan baku yang efektif dan pemesanan kembali yang optimal (Milne, Mahapatra, \& Wang, 2015).

Implementasi MRP pada konstruksi jalan layang non tol Kampung Melayu - Tanah Abang, diperoleh biaya pengadaan material yang paling rendah adalah menggunakan matode Lot For Lot (Vially \& Angreni, 2013). Penerapan MRP mampu mengefektifkan biaya persediaan sebesar $46,7 \%$ pada perusahaan gangsar (Wahyuni \& Syaichu, 2015).

Masalah utama yang sering terjadi pada saat produksi kertas ini adalah material yang tersedia dalam gudang kadang kala tidak tepat dengan perencanaan schedule produksi yang berjalan. Material yang ada dalam inventory terkadang tidak memenuhi untuk pembuatan suatu produk yang telah dipesan dan di jadwalkan untuk diproduksi pada waktu tertentu. Material yang ada di dalam gudang sering tidak tepat, ada kalanya jumlah material di dalam gudang over materials sehingga biaya yang dikeluarkan perusahaan akan bertambah seiring banyaknya material yang tersedia di dalam gudang. Ada juga jumlah material dalam gudang tidak memenuhi jumlah yang dibutuhkan untuk diproses dalam produksi yang terjadwal, sehingga akan menyebabkan produksi dalam perusahaan terganggu.

Penelitian ini bertujuan merencanakan kebutuhan material di masa mendatang dan membandingkan biaya perencanaan kebutuhan material dengan biaya yang dikeluarkan perusahaan. Hasil penelitian ini diharapkan menjadi alternatif perusahaan dalam penerapan metode yang sesuai dengan kondisi perusahaan.

\section{METODE PENELITIAN}

Penelitian ini dilakukan pada sebuah prusahaan kertas Data penelitian yang digunakan adalah data permintaan kertas pada bulan Juli 2017 sampai dengan Juli 2018.

\section{Peramalan}

Peramalan adalah kegiatan mhan di masa mendatang berdasarkan data historis yang telah ada (Chase, Jacobs\& Aquilano, 2004). Peramalan bertujuan untuk meminimalkan ketidakseimbangan antara perkiraan yang diperoleh dengan aktual di masa mendatang. Ketepatan peramalan menjadi penting sebagai dasar pengukuran data yang sudah ada dengan data peramalan yang dilakukan (Karuniawan, Supriyadi, \& Ramayanti, 2017).

Menurut Heizer dan Render (2010) peramalan kuantitatif merupakan peramalan yang menggunakan model matematis berdasarkan data historis dan variabel sebab akibat. Beberapa metode peramalan kuantitatif yang digunakan dalam penelitian ini adalah sebagai berikut:

a. Regresi Linier (Linear Regression)

Model peramalan yang menggambarkan hubungan fungsional antara variabel bebas dan terikat.

$$
\hat{\mathbf{y}}=\mathbf{a}+\mathbf{b X}
$$

ŷ : besarnya nilai peramlan

a : persilangan sumbu y

b : kemiringan garis regresi

$\mathrm{X}$ : variabel bebas

b. Rata-rata Bergerak tertimbang (Weighted Moving Average)

Metode peramalan dengan mengkombinasikan data berdasarkan penambahan bobot dengan pembobotan yang terbesar pada data terakhir yang masuk dalam periode perhitungan rata-rata (Ferdinand, 2012).

$\boldsymbol{F t}=\frac{\Sigma(\text { bobot periode } \mathbf{n})(\text { permintaan periode } \mathbf{n})}{n}$.

\section{c. Penghalusan Eksponensial (Eksponential} Smoothing)

metode peramalan yang menggunakan pencatatan masa lalu yang sedikit dan pembobotan titik data menggunakan fungsi eksponensial (Savira, \& Moeliono, 2014).

$$
\mathrm{Ft}=\mathrm{Ft}-1+\alpha(\text { At-1 }- \text { Ft-1) }
$$

Ft : peramalan baru

Ft-1 : peramalan sebelumnya

A : konstanta penghalusan (pembobotan) $(0 \leq \alpha \leq 1)$

At-1 : permintaan aktual periode lalu

Perbedaan nilai peramalan dengan data aktual merupakan kesalahan peramalan. Model yang mempunyai tingkat kesalahan yang paling kecil merupakan metode yang paling mendekati dengan aktual. Tingkat kesalahan peramalan dapat diketahui dengan menggunakan metode nilai kesalahan sebagai (Heizer dan Render, 
2010) :

a. Mean Absolute Deviation (MAD)

MAD merupakan tingkat kesalahan dengan cara merata-ratakan nilai absolut error (penyimpangan) seluruh hasil peramalan Sungkawa, \& Megasari, 2011).

$$
M A D=\frac{\Sigma \mid \text { aktual }- \text { peramalan } \mid}{n}
$$

b. Mean Squared Error (MSE)

MSE merupakan rata-rata selisih kuadrat antara nilai yang diramalkan dan yang diamati.

$M S E=\frac{\Sigma(\text { kesahalan peramalan })^{2}}{n}$

C. Mean Absolute Percentage Error (MAPE)

$M A P E=\frac{100 \sum_{\mathrm{i}-1}^{\mathrm{n}} \mid \text { aktual } \mathrm{i}-\text { ramalan } \mathrm{i} \mid \text { aktual } \mathrm{i}}{n}$

\section{Material Requirement Planning (MRP)}

MRP merupakan metode penentuan kebutuhan bahan baku yang akan digunakan berdasarkan model permintaan terikat status permintaan, perkiraan penerimaan dan jadwal produksi induk (Dewi, \& Saroso, 2016). Penerapan suatu MRP memiliki proses yang terdiri atas empat langkah utama, yaitu (1) menyusun BOM, (2) menghitung kebutuhan bersih bahan baku (net requirement), (3) melakukan lot sizing, dan (4) menyusun timephasing requirement. Proses ini dilakukan berulang kali, merinci setiap struktur produk hingga semua komponen dibuatkan jadwalnya.

Lot Size merupakan besarnya pesanan per item yang akan dipesan berdasarkan data kuantitas pesanan dari item berdasarkan data MRP.

1. Teknik Fixed Order Quantity (FOQ)

Fixed Order Quantity (FOQ) merupakan konsep pemesanan dengan jumlah yang sangat besar secara periodik yang disebabkan keterbatasan fasilitas.

2. Teknik Lot for Lot (LFL)

Teknik ini memproduksi secara tepat berapa kebutuhan bahan baku yang diperlukan. Teknik ini bertujuan untuk memenuhi kebutuhan permintaan yang bersifat terikat. Bila pesanan yang terjadi ekonomis dan teknik persediaan just in time diterapkan, maka teknik ini sangat efisien (Heizer dan Render, 2010)
3. Teknik Fixed Period Requirement (FPR)

Metode pemesanan secara periodik berdasarkan kebutuhan selama periode tersebut.

4. Teknik Economic Order Quantity (EOQ)

Teknik EOQ merupakan teknik statistik yang menggunakan rata-rata seperti permintaan satu bulan atau satu tahun (Heizer dan Render,2010)

$Q=\sqrt{\frac{2 D S}{H}}$

$Q \quad$ : ukuran lot yang akan dipesan,

$D$ : kebutuhan per tahun,

$S \quad$ : biaya pemesanan per order

$H \quad$ : biaya penyimpanan per unit per tahun

5. Teknik Period Order Quantity (POQ)

Teknik $\mathrm{POQ}$ sering disebut juga sebagai metode Uniform Order Sycle, merupakan pengembangan dari metode EOQ untuk jumlah permintaan yang tidak sama dalam beberapa periode. Rata-rata permintaan digunakan dalam model (Herjanto, 2008)

$P O Q=Q=\sqrt{\frac{2 S}{D H}}$

$Q \quad$ : ukuran lot yang akan dipesan

$D$ : kebutuhan per tahun

$S \quad$ : biaya pemesanan per order

$H$ : biaya penyimpanan per unit per tahun

\section{HASIL DAN PEMBAHASAN}

Pengolahan data berdasarkan data historis perusahaan yaitu data permintaan selama juli 2017 sampai Juli 2018 (Tabel 1) dan Bill of Material kertas (Gambar 1). Data diolah dengan teknik peramalan untuk mendapatkan hasil peramalan terbaik yang akan digunakan untuk membuat Material Requirement Planning (MRP).

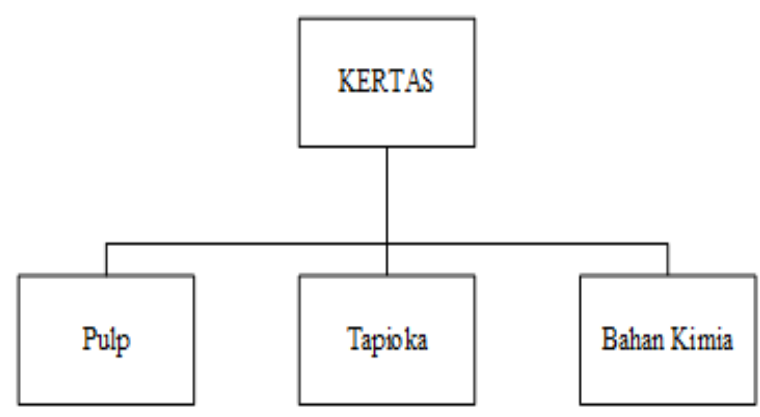

Gambar 1. BOM Kertas 
Tabel 1. Data Permintaan Kertas

\begin{tabular}{|c|c|c|}
\hline No $_{0}$ & Bulan & Demand (Ton) \\
\hline 1 & Juli 2017 & 296 \\
\hline 2 & Agustus 2017 & 387 \\
\hline 3 & September 2017 & 393 \\
\hline 4 & Oktober 2017 & 263 \\
\hline 5 & November 2017 & 410 \\
\hline 6 & Desember 2017 & 562 \\
\hline 7 & Januari 2018 & 302 \\
\hline 8 & Februar 2018 & 281 \\
\hline 9 & Maret 2018 & 406 \\
\hline 10 & April 2018 & 508 \\
\hline 11 & Mei 2018 & 417 \\
\hline 12 & Juni 2018 & 569 \\
\hline 13 & Juli 2018 & 526 \\
\hline
\end{tabular}

Tabel 2. Hasil Uji Akurasi Pengendalian Peramalan

\begin{tabular}{|l|c|c|c|c|c|}
\hline No. & Metode Peramalan & MAD & MSE & MAPE & Keterangan \\
\hline 1 & Persamaan Linear & 70.65597 & 7596.929 & 18.89784 & Terkecil \\
\hline 2 & Moving Averagen $=3$ & 99.2667 & 15294.6 & 24.8717 & \\
\hline 3 & Moving Average $n=6$ & 91.0238 & 12549.2 & 158.001 & \\
\hline 4 & Exponential Smoothing $\alpha=0.1$ & 110.092 & 17492.1 & 24.6547 & Terbesar \\
\hline 5 & Exponential Smoothing $\alpha=0.4$ & 98.7698 & 13480.8 & 24.5462 & \\
\hline
\end{tabular}

Dari hasil peramalan yang telah dilakukan diperoleh bahwa metode peramalan yang memberikan nilai simpangan terkecil adalah metode Regresi Linear (tabel 2). Langkah selanjutnya adalah membuat Jadwal Induk Produksi (Master Production Schedule/MPS) sesuai dengan ramalan permintaan yang didapat (Tabel 3).

Tabel 3. MPS

\begin{tabular}{|c|c|c|c|}
\hline \multicolumn{5}{|c|}{ MPS Kertas } \\
\hline Periode & Permintaan & $\begin{array}{c}\text { Peramalan } \\
\text { (Regresi Linear) }\end{array}$ & MPS \\
\hline 1 & 296 & 315.868 & 316.000 \\
\hline 2 & 387 & 331.428 & 331.600 \\
\hline 3 & 393 & 346.989 & 347.000 \\
\hline 4 & 263 & 362.549 & 362.600 \\
\hline 5 & 410 & 378.11 & 378.200 \\
\hline 6 & 562 & 393.670 & 393.800 \\
\hline 7 & 302 & 409.230 & 409.400 \\
\hline 8 & 281 & 424.791 & 424.800 \\
\hline 9 & 406 & 440.351 & 440.400 \\
\hline 10 & 508 & 455.91 & 456.000 \\
\hline 11 & 417 & 471.472 & 471.800 \\
\hline 12 & 569 & 487.032 & 487.200 \\
\hline 13 & 526 & 502.593 & 502.600 \\
\hline
\end{tabular}

Tabel 4. Data BOM Kertas

\begin{tabular}{|c|c|c|c|c|c|}
\hline No & Level & Material & $\begin{array}{c}\text { Jumlah } \\
(\mathrm{Kg})\end{array}$ & Lead Time & $\begin{array}{c}\text { On Hand } \\
\text { (Ton) }\end{array}$ \\
\hline 1 & 0 & KERTAS & 200 & 1 Bulan & \\
\hline 2 & 1 & Pulp & 813.91 & 1 Bulan & 500 \\
\hline 3 & 1 & Tapioka & 150.17 & 1 Bulan & 150 \\
\hline 4 & 1 & Bahan Kimia & 10.23 & 1 Bulan & 10 \\
\hline
\end{tabular}

\section{Fixed Order Quantity (FOQ)}

Teknik FOQ menggunakan kuantitas pemesanan yang tetap untuk suatu persediaan item tertentu berdasarkan faktor intuitif atau dapat dilakukan secara bebas. Tabel 5 merupakan pemakaian teknik FOQ dengan ukuran lot sesuai dengan material.

Tabel 5. Biaya Perencanaan Kebutuhan Material dengan Metode FOQ

\begin{tabular}{|c|c|c|c|c|c|c|c|}
\hline \multicolumn{8}{|c|}{ Biaya Perencenanann Kebutuhan Material Dengam Metode FOQ } \\
\hline \multirow{2}{*}{ Naterial } & \multicolumn{3}{|c|}{ Pesman } & \multicolumn{3}{|c|}{ Simpan } & \multirow{2}{*}{ Total Biaya } \\
\hline & Jumlah & Biaya & T. Biaya & Jumlah & Biaya & T. Biara & \\
\hline Pulp & 8 & $\$ 3.803,87$ & S30.430,92 & 3365,25 & S749,24 & $825251.378,01$ & S 2.551.808,94 \\
\hline Tapioka & 5 & \$3.803,87 & S 19.019,33 & $\begin{array}{l}959,01 \\
\end{array}$ & $\$ 359,24$ & S 344.5160,02 & $8366.353,35$ \\
\hline Bahan Kimia & 6 & \$1.034.17 & $86.205,00$ & 60,67 & 8596,24 & S36.175,61 & $842,30,60$ \\
\hline & & Bivar Der & 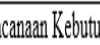 & the & & & $\$ 2.957,724,59$ \\
\hline
\end{tabular}

\section{Lot for Lot (LFL)}

Teknik ini melakukan perhitungan kembali (bersifat dinamis) jika terjadi perubahan pada kebutuhan bajan baku yang digunakan. Tabel 6 memperlihatkan hasil perhitungan dengan menggunakan Lot For Lot.

Tabel 6. Biaya Perencanaan Kebutuhan Material dengan Metode LFL

\begin{tabular}{|c|c|c|c|c|c|c|c|}
\hline \multicolumn{8}{|c|}{ Biaya Perencennaan Kebutuhan Material Dengam Metode LFL } \\
\hline \multirow{2}{*}{ Material } & \multicolumn{3}{|c|}{ Pesan } & \multicolumn{3}{|c|}{ Simpan } & \multirow{2}{*}{ Total Biaya } \\
\hline & Jumlah & Biaya & T. Biaya & Jumlah & Biaya & T. Biaya & \\
\hline Pulp & 12 & $\$ 3.803,87$ & \& 45.646,39 & 234,67 & \$749,24 & $\$ 1775.802,52$ & $\$ 221.466,90$ \\
\hline Tapioka & 11 & $\$ 3.803,87$ & S 41.842,52 & 152,29 & $\$ 359,24$ & $554.799,66$ & $\$ 96.552,18$ \\
\hline Bahan Kimia & 11 & $\$ 1.034 .17$ & $\$ 11.375,83$ & 7,78 & \$596,24 & $\$ 4.640,95$ & $\$ 16.016,77$ \\
\hline \multicolumn{7}{|c|}{ Biava Perencennanan Kebutuhan Naterial } & $\$ 3344.035,8 \mathrm{C}$ \\
\hline
\end{tabular}

\section{Fixed Period Requirements (FPR)}

Teknik FPR merupakan teknik pemesanan kembali dengan selang waktu antar pemesanan tetap berdasarkan interval pemesanan yang konstan dan bervariasi. Biaya pemesanan dengan menggunakan metode ini sesuai dengan tabel 7. 
Tabel 7. Biaya Perencanaan Kebutuhan Material dengan Metode FPR

\begin{tabular}{|c|c|c|c|c|c|c|c|}
\hline \multicolumn{8}{|c|}{ Biaya Perencananan Keoutuhan Vaterial Dengam Metode PRR } \\
\hline \multirow{2}{*}{ Material } & \multicolumn{3}{|c|}{ Pesan } & \multicolumn{3}{|c|}{ Simpan } & \multirow{2}{*}{ Total Biaya } \\
\hline & Jumlah & Biaya & T. Biaya & Jumlah & Biaya & T. Biaya & \\
\hline Pulp & 5 & $\$ 3.803,87$ & S 19.019,33 & 4023,27 & S749,24 & $\$ 3.014+393,39$ & S3.0333412,71 \\
\hline Tapioka & 5 & $\$ 3.803,87$ & $\$ 19.019,33$ & 742,30 & 8359,24 & S 266.665,12 & $\$ 285.684,45$ \\
\hline Bahan Kimia & 5 & $\$ 1.034 .17$ & S5.170,83 & 61,43 & $\$ 596,24$ & $\int 36.66675$ & $\$ 41.797,58$ \\
\hline & & & 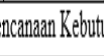 & out & & & \$3.360.994,74 \\
\hline
\end{tabular}

\section{Economic Order Quantity (EOQ)}

Teknik EOQ berdasarkan ukuran lot tetap, biaya simpan dan biaya simpan. Teknik ini menggunakan perencanaan secara horison dan efektif jika kebutuhan konstan dan kebutuhan bersifat terus menerus. Tabel 8 diperlihatkan hasil perhitungan dengan menggunakan teknik Economic Order Quantity

Tabel 8. Biaya Perencanaan Kebutuhan Material dengan $E O Q$

\begin{tabular}{|c|c|c|c|c|c|c|c|}
\hline \multicolumn{8}{|c|}{ Biaya Perencenanaan Kebutuhan Material Dengam Metode EOQ } \\
\hline \multirow{2}{*}{ Material } & \multicolumn{3}{|c|}{ Pesan } & \multicolumn{3}{|c|}{ Simpan } & \multirow{2}{*}{ Total Biaja } \\
\hline & \begin{tabular}{|l|} 
Jumlan \\
\end{tabular} & Biaya & T. Biaya & Jumlath & Biaya & T. Biaya & \\
\hline Pulp & 12 & $\$ 3.803,87$ & $\$ 45.646,39$ & 666,77 & $\$ 749,24$ & S 499.568,95 & S $545,215,33$ \\
\hline Tapioka & 11 & $\$ 3.803,87$ & $\$ 41.842,52$ & 371,09 & $\$ 359,24$ & $\$ 133,311,76$ & $\$ 175.153,76$ \\
\hline Bahan Kimia & 11 & $\$ 1.034 .17$ & $\$ 11.757,83$ & 28.61 & 5596,24 & $\$ 17.056,09$ & \$ 28.431 .92 \\
\hline & & Biaya Perenc & canaran Keoutulu & $a n a_{2}$ & & & $\$ 748,801,01$ \\
\hline
\end{tabular}

\section{Period Order Quantity (POQ)}

Teknik POQ hampir sama dengan FPR dengan perbedaan pada interval pemesanan berdasarkan perhitungan logika EOQ klasik yang telah dimodifikasi. Tabel 9 menunjukkan hasil biaya pemesanan berdasarkan perhitungan $P O Q$.

Tabel 9. Biaya Perencanaan Kebutuhan Material dengan Metode POQ

\begin{tabular}{|c|c|c|c|c|c|c|c|}
\hline \multicolumn{8}{|c|}{ Biaya Perencunaan Kebutuhan Material Dengam Metode POQ } \\
\hline \multirow{2}{*}{ Material } & \multicolumn{3}{|c|}{ Pesan } & \multicolumn{3}{|c|}{ Simpan } & \multirow{2}{*}{ Total Biaya } \\
\hline & Jumlah & Biaya & T. Biaya & Jumlah & Biaya & T. Biaya & \\
\hline Pulp & 11 & $\$ 3.803,87$ & $\$ 4.842,52$ & 517.09 & $\$ 749,24$ & $8387,466,09$ & \$ 429.268,61 \\
\hline Tapioka & 11 & $\$ 3.803,87$ & $\$ 41.842,52$ & 153,89 & $\$ 359,24$ & $5550.018,89$ & $\$ 96.861,41$ \\
\hline Bahan Kimia & 11 & $\$ 1.034 .17$ & $\$ 11.375 .83$ & 10.26 & $\$ 596,24$ & $\$ 6.117,91$ & $\$ 17.493,74$ \\
\hline & & Biaya Perenc & annann Kabuth & Wan Wate & & & $5543,623,76$ \\
\hline
\end{tabular}

Dari hasil perhitungan perencaan material diatas maka biaya paling minimum untuk perencanaan material yaitu, metode Lot For Lot (LFL) dan biaya perencanaan paling besar yaitu metode Fixed Period Requirements (FPR) (Tabel 10). Sementara itu kebijakan perusahaan selama ini adalah menggunakan metode Fixed Period Requirements (FPR). Dengan hasil perhitungan diatas maka seharusnya perusahaan bisa menggunakan metode Lot For Lot (LFL) sebagai acuan untuk merencanakan kebutuhan meterial di masa yang akan datang.

Tabel 10. Perbandingan Biaya MRP

\begin{tabular}{|c|c|c|}
\hline \multicolumn{3}{|c|}{ Perbandingan Biaya MRP } \\
\hline No & Metode & Biaya \\
\hline 1 & Fixed Order Quantity (FOQ), & $\$ 2.957 .724,89$ \\
\hline 2 & Lot for Lot (LFL) & $\$ 334,035,86$ \\
\hline 3 & Metode Fixed Period Requirements (FPR) & $\$ 3,360.894,74$ \\
\hline 4 & Economic Order Quantity (EOQ) & $\$ 748.801,01$ \\
\hline 5 & Period Order Quantity (POQ) & $\$ 543.623,76$ \\
\hline
\end{tabular}

\section{KESIMPULAN}

Dari hasil analisa yang telah dilakukan diperoleh hasil bahwa metode peramalan yang paling efektif adalah metode Regresi Linear dengan nilai MAD sebesar 70.65597, MSE sebesar 7596.929, dan MAPE sebesar 18.89784. Metode perencanaan kebutuhan material yang efektif dengan biaya paling murah adalah dengan menggunakan metode Lot For Lot sebesar \$ 164.48. Akan tetapi metode ini akan sulit untuk diterapkan dikarenakan jumlah ketersediaan bahan baku pembuatan material yang terbatas sehingga untuk menerapkan metode ini akan sulit untuk diterapkan. Implementasi metode Lot For Lot bila dibandingkan dengan metode yang dipakai perusahaan yaitu merencanakan kebutuhan material per tiga bulan dengan metode Fixed Period Requirements (FPR) mampu menurunkan biaya sebesar $90,06 \%$.

\section{DAFTAR PUSTAKA}

Arif, M., Supriyadi, S., \& Cahyadi, D. (2017). Analisis Perencanaan Persediaan Batubara FX Dengan Metode Material Requirement Planning. Jurnal Manajemen Industri dan Logistik, 1(2), 53-60.

Chase R B., Jacobs R F., \& Aquilano N J. (2004). Operations Management For Competitive Advantage. New York: Mc Graw Hill.

Dewi, P. S., \& Saroso, D. S. (2016). Implementasi Material Requirements Planning (MRP) pada Perencanaan Persediaan Material Panel Listrik di PT. TIS. Sinergi: Jurnal Teknik Mercu Buana, 20(1), 36-46. 
Ferdinand, E. (2012). Analisis Peramalan Volume Penjualan Dengan Perbandingan Cara Manual Dan Program QSB Pada PT. Lion Wings.

Greasley, A. (2008). Operations management. Operations Management. Thousand Oaks: SAGE Publications Inc.

Heizer, J., \& Render, B. (2010). Manajemen Operasi. Jakarta: Salemba Empat.

Herjanto, E. (2008). Manajemen Operasi. Jakarta: PT. Grasindo.

Karuniawan, A., Supriyadi, S., \& Ramayanti, G. (2017). Optimalisasi Sistem Persediaan Bahan Baku Natrium Persulfate Dengan Metode Lot Sizing. In Prosiding Seminar Nasional Riset Terapan/ SENASSET(pp. 151-157).

Milne, R. J., Mahapatra, S., \& Wang, C. T. (2015). Optimizing planned lead times for enhancing performance of MRP systems. International Journal of Production Economics, 167(1), 220-231.

Savira, M., \& Moeliono, N. N. K. (2014). Analisis Peramalan Penjualan Obat Generik Berlogo (Ogb) Pada Pt. Indonesia Farma. eProceedings of Management,1(3), 1-13

Sungkawa, I., \& Megasari, R. T. (2011). Penerapan Ukuran Ketepatan Nilai Ramalan Data Deret Waktu dalam Seleksi Model Peramalan Volume Penjualan PT Satriamandiri Citramulia. ComTech: Computer, Mathematics and Engineering Applications, 2(2), 636-645

Vially, J., \& Angreni, I. A. A. (2013). Aplikasi Metode MRP (Material Requirement Planning) Terhadap Material Pasir, Semen Dan Besi Tulangan Pada Konstruksi Jalan Layang. Prosiding PESAT, (pp. T41-T48).

Wahyuni, A., \& Syaichu, A. (2015). Perencanaan Persediaan Bahan Baku dengan Menggunakan Metode Material Requirement Planning (MRP) Produk Kacang Shanghai pada Perusahaan Gangsar Ngunut-Tulungagung. Spektrum Industri, 13(2), 141-156. 